\title{
Cultura escolar e disciplina na formação de professores: a Escola Normal de Montes Claros (1888-1903)
}

\author{
School culture and discipline in teacher training: \\ the Normal School of Montes Claros (1888-1903)
}

Wenceslau GONÇALVES NETO ${ }^{1}$

Carlos Henrique de CARVALHO²

\begin{abstract}
Resumo
A Escola Normal de Montes Claros foi criada em 1879, funcionando regularmente até 1905 , quando sofre sua primeira interrupção. A documentação permite perceber diversos ângulos da cultura da escola: configuração das relaçôes institucionais, com reformas no regulamento, currículo, delimitação e vigilância do espaço, do uniforme escolar; manifestações indisciplinares: aluno-professor, aluno-aluno(a) e aluno-funcionário; esforço pela preservação da autoridade de professores, diretor e funcionários; diferentes manifestaçóes de inaceitação da disciplina por parte dos alunos; tipos e formas de puniçôes. Percebe-se um movimento na moldagem de uma cultura que envolve currículo, disciplina, preservaçáo da autoridade e controle das relaçôes entre os educandos.
\end{abstract}

Palavras-chave: Cultura Escolar. Disciplina. Escola Normal. Minas Gerais.
Abstract

The Normal School of Montes Claros was created in 1879, functioning regularly until 1905 , when it undergoes its first interruption. The documentation allows to perceive several angles of the school culture: configuration of the institutional relations, with reforms in the regulation, curriculum, delimitation and surveillance of the space, of the school uniform; indisciplinary manifestations: student-teacher, student-student and student-employee; effort to preserve the authority of teachers, principals and staff; different manifestations of students' inacceptance of discipline; types and forms of punishment. It is perceived a movement in the molding of a culture that involves curriculum, discipline, preservation of authority and control of the relations among students.

Keywords: School Culture. Discipline. Normal School. Minas Gerais.

1 Doutor em História pela Universidade de São Paulo (USP). Professor dos Programas de Pós-Graduaçáo em Educaçāo da Universidade de Uberaba (UNIUBE) e Universidade Federal de Uberlândia (UFU). Bolsista Produtividade em Pesquisa do CNPq e do Programa Pesquisador Mineiro da FAPEMIG. Av. Nenê Sabino, 1801, bairro Universitário, Uberaba-MG, CEP: 38.055-500, tel.: (34) 3319-8811. Email: <wenceslau@ufu.br>.

2 Doutor em História pela Universidade de São Paulo (USP). Professor da Faculdade de Educaçáo e do Programa de Pós-Graduação em Educação da Universidade Federal de Uberlândia (UFU). Bolsista Produtividade em Pesquisa do CNPq e do Programa Pesquisador Mineiro da FAPEMIG. Av. João Naves de Ávila, 2121, bairro Santa Mônica, Uberlândia-MG, CEP: 38408-100, tel.: (34) 3239-4411. Email: <carloshcarvalho06@yahoo.com.br>.

R. Educ. Públ.

Cuiabá

v. 27

n. $65 / 1$

p. $507-528$ maio/ago. 2018 
A educação foi, é e provavelmente continuará sendo um desafio para o Brasil e para os países da América Latina, que enfrentam problemas semelhantes, consideradas as singularidades, respeitantes a financiamento, continuidade nas políticas educacionais, organização e sincronização dos níveis de ensino, qualidade do conjunto, formação de professores, etc. Esses problemas não são recentes e, apesar de terem sido identificados há muito tempo, perduraram ao longo da história e se apresentam nos dias de hoje como ameaças ao processo de desenvolvimento e ao futuro, espalhando nuvens escuras sobre o horizonte de nossos alunos e podendo transformar em pesadelo os sonhos de nossas crianças. Essa situação foi denunciada, reiteradamente, ao longo dos últimos 200 anos, desde o período de independência da América Latina, que se configura nas primeiras décadas do século XIX. Apesar da diversidade de alternativas tentadas pelos países da regiấo, alguns mais cedo, outros mais tardiamente, continuamos no século XXI em busca de um modelo de educação e de escola que nos auxilie no processo de implantação de um sistema eficiente e eficaz de educação, como os que foram estabelecidos pelos países europeus no século XIX.

Procuramos escolher, para esta análise, uma abordagem que perpassa a história da educação brasileira - e também dos países latino-americanos - no seu esforço para instauração da instrução popular: a formaçáo de professores pelas escolas normais na segunda metade do século XIX. Evitando repetir discussóes já efetuadas por muitos pesquisadores sobre as origens e disseminação desse tipo de escola no Brasil, procuraremos recuperar uma parcela do cotidiano de uma escola normal de uma cidade interiorana, Montes Claros, de um estado também interiorano, Minas Gerais, mas a partir da qual, utilizando categorias de análise que apresentaremos adiante, pretendemos demonstrar as relaçóes de poder externas à escola, como a competência estadual de escolher o local para a instituição, contratar professores, definir currículo, etc., bem como as relaçóes de poder internas, envolvendo professores, alunos, funcionários, controle do tempo, gestão disciplinar, etc. Será uma incursão de certo modo pontual, mas que pretende oferecer elementos que possibilitem perceber nuances do processo de formação de professores primários num momento em que o país e o estado de Minas Gerais ainda estavam envoltos pela mudança de regime político (Império para República) e em dados estatísticos que indicavam mais de $80 \%$ de analfabetos em sua população. Os desafios brasileiros e do estado de Minas Gerais no campo da educação naquele momento eram muitos, relacionados à falta de professores, número reduzido de escolas normais, incapacidade de mantê-las em funcionamento ininterrupto, busca de métodos eficazes de formação, baixos salários de seus professores, infraestrutura deficiente, entre outros, mas não eram menos numerosos também no interior das escolas normais, se considerarmos aspectos das relaçôes professor-aluno, distribuiçẫo do tempo, gestão, hierarquia, etc. 
Ao voltarmos nossos olhos para a perspectiva histórica não estamos desprezando os enfrentamentos do presente, pelo contrário, consideramos que não existe pesquisa sobre o passado desvinculada dos problemas que hoje nos afetam. Passado e presente se intercomunicam necessariamente e se iluminam complementarmente. Vamos ao passado por conta daquilo que nos incomoda no momento e o passado nos permitirá maior compreensão sobre as origens do problema, seus desdobramentos ao longo do tempo, as tentativas que já foram apresentadas para sua superação, a vontade política expressa pelos agentes sociais, as demandas e os conflitos gerados pelas diferentes classes, as mudanças e permanências, para retornamos ao presente e, com novos olhos, nos posicionarmos. Como historiadores, essa é a tarefa a que nos propomos.

Para efetivar essa contribuição, bem como para estabelecer as pontes entre passado e presente, entre os vários aspectos abordados, daremos maior ênfase a um tema que tem persistido nas manchetes das diversas formas de imprensa, em estudos acadêmicos, nos relatos de professores, alunos, pais e responsáveis pelas escolas, relacionado à violência escolar, aos conflitos disciplinares, às relaçóes professor-aluno, em suma, às relaçóes de poder no interior das escolas e que são abordados, por exemplo, com destaques para a violência continuada contra professores, pela relação entre fracasso escolar e disciplina, etc. (PINHO; MARIAN, 2017; MATTOS; COELHO, 2011). Nossa escolha pela escola normal de Montes Claros, portanto, não se dá propriamente por aspectos pedagógicos ou de política educacional, mas estará centrada na preocupação de fornecer elementos que nos permitam pensar a questão do poder, da violência, dos conflitos intraescolares ao longo do tempo e, consequentemente, refletir com mais propriedade sobre os problemas que nos afligem no presente.

Neste texto procuramos descrever e analisar concepçóes de educaçáo, cotidiano do trabalho docente, estabelecimento e cumprimento de normas disciplinares, organização do espaço escolar, definição de comportamentos aceitáveis e não aceitáveis, determinação de puniçōes aos que fogem às regras, etc., no interior da Escola Normal de Montes Claros, no Estado de Minas Gerais, entre os anos de 1887 a 1903. Essa periodização não está ligada a datas especiais na vida da escola, mas à disponibilidade de informaçôes contidas no livro Atas da Congregação dos professores da Escola Normal de Montes Claros (MINAS GERAIS, 1887-1903) ${ }^{3}$. A não localização, no estágio atual da pesquisa, de documentação complementar

3 Todas as citaçōes de atas adiante provêm desse livro. Estado de conservação do documento, desgaste da tinta, etc., geraram em alguns momentos lacunas ou dúvidas na transcriçấo, que estão devidamente destacadas. 
impediu a extensão do estudo tanto à origem da Escola Normal de Montes Claros, que começa seu funcionamento em 1880, como à sua continuidade até 1905, quando suas atividades são suspensas por determinação do governo do estado de Minas Gerais, por conta de problemas financeiros e de mudanças na política educacional.

De qualquer forma, o conteúdo do livro de atas é bastante rico e nos permite variadas incursóes por diferentes temáticas, ligadas aos aspectos selecionados e a outros não menos importantes. Nesse momento, fizemos o presente recorte na documentação para não apenas discutir uma questão significativa no interior da História da Educação, mas também oportunizar a difusão de parte do seu conteúdo e chamar a atenção para as oportunidades oferecidas pelo conjunto documental disponível nos arquivos mineiros.

Também buscou-se compreender, no conjunto dessas relaçóes que se estabelecem entre os agentes envolvidos - professores, diretor, alunos, funcionários - a formação do que poderemos chamar de uma cultura escolar, já que os elementos fundamentais da organizaçáo da escola encontram-se aí explicitados. O recorte voltado para a questão disciplinar é apenas uma opção, na busca de ângulos de visão que se possam estabelecer sobre a realidade escolar enfocada. Nesse horizonte metodológico é fundamental pensar o cotidiano escolar imerso no contexto que envolve a escola, bem como que esse espaço é também perpassado por culturas, que se manifestam dentro da escola ou fora dela. No espaço da escola as culturas se relacionam, orientam valores, práticas escolares e representaçóes da e sobre a escola.

Em torno da cultura escolar existem muitas discussôes relevantes (VIDAL; SCHWARTZ, 2011), mas neste estudo estamos acompanhando o que foi apresentado por Dominique Julia (2001, p. 10, grifos do autor) em texto bastante conhecido entre os historiadores da educação:

[...] um conjunto de normas que definem conhecimentos a ensinar e condutas a inculcar, e um conjunto de práticas que permitem a transmissão desses conhecimentos e a incorporação desses comportamentos; normas e práticas coordenadas a finalidades que podem variar segundo as épocas (finalidades religiosas, sociopolíticas ou simplesmente de socialização).

Nessa perspectiva, a historiografia da educação tem buscado compreender como a cultura escolar se manifesta no âmbito dos ambientes educativos. Náo obstante, é importante questionarmos algumas análises que focam a escola como um universo em si mesmo, ou seja, a ideia de que a escola produz uma 
cultura a partir dela, sem visualizá-la como parte de um todo, que o influencia e é influenciada por ele. Nessa direção, observa Thais Nívea de Lima Fonseca (2003, p. 63):

Práticas docentes, processos de escolarização, práticas educativas e idéias pedagógicas não podem ser pensados em si, nem somente em sua relação com o que podemos chamar de universo escolar, como uma instância autônoma (que na verdade não é). Estáo impregnadas da pluralidade de aspectos presentes nas relaçôes estabelecidas cotidianamente entre grupos e indivíduos.

Atentos a esses cuidados, procuraremos desenvolver alguns eixos, em torno dos quais buscaremos lançar luz a partir dos dados encontrados no livro de atas. Esses referenciais, relacionados com a questão da organização regimental, com os tipos de indisciplina registrados, com os procedimentos voltados para a preservação da ordem e da autoridade, com a percepção das formas de resistência ou de oposiçáo por parte dos alunos ao estatuído e, finalmente, com a aplicação de penas diversas sobre os discentes, a partir do regulamento e das discussóes que são implementadas nas reunióes da congregação.

Como resultado, cremos ter conseguido captar e caracterizar parcelas expressivas do cotidiano escolar de uma escola de formação de professores no interior de Minas Gerais, no final do Império e nos anos iniciais da República, o que poderá contribuir para a compreensão desse momento de transição e das preocupaçóes educacionais que se encontravam presentes nos planos local, estadual e nacional.

\section{A Escola}

Montes Claros situa-se na região Norte do estado de Minas Gerais e tem sua autonomia municipal estabelecida em meados do século XIX. O desenvolvimento das cidades da região está ligado ao ciclo minerador do século XVIII e, com seu declínio, sofrerá sequelas que levam a uma certa estagnaçáo na segunda metade do século XIX. Montes Claros, no entanto, permanece com destaque regional, ampliando sua infraestrutura e a população, posição que mantém no início do século XX (BRASIL, 1983; VIANNA, 1964). A criação de uma escola normal por parte do governo estadual nessa cidade será, portanto, uma iniciativa que responderia à necessidade de formação de professores para atender uma grande região, além das demandas da própria localidade. 
Urbino de Sousa Vianna (1916, p. 100), memorialista de Montes Claros, chama a atençáo para o significado da escola normal para a cidade:

Montes Claros, sem ser propriamente uma cidade de feição intellectual é, no entretanto, um nucleo onde se move a intelligencia com alguma largueza, garantida a liberdade de pensamento, senão em toda sua plenitude, o bastante para desenvolver e fazer evoluir o pensamento. Foi séde de uma Escola Normal que chegou a ser classificada como segunda no Estado, pela alta importancia e consideração que os docentes davam ao ensino; viveiro de moços que se formaram sob a direcção de mestres tais como Carlos Sá Junior, Camillo Prates, Antonio Pereira dos Anjos, Pedro Augusto Teixeira Guimarães, José Rodrigues Prates e João Antonio Gonçalves Chaves, dando elevado numero de discípulos, dos quaes muitos hoje honram o magistério, tendo outros se elevado a posições salientes.

Criada em 1879, essa escola entrará em funcionamento a partir de 1880, inicialmente em uma casa alugada para esse fim e, posteriormente, em prédio especialmente para ela construído. Existem estudos que remetem a dados objetivos do funcionamento da instituição ao longo do período de 1880 a 1905 , como número de alunos e de diplomas registrados, número de professores, etc. (DURÃES, 2012; OLIVEIRA; ALVES FILHO, 2012), bem como discussóes recentes sobre a criação de escolas de formação de professores no Brasil (ARAUJO; FREITAS; LOPES, 2008). Não nos deteremos sobre eles por não ser esse o objetivo do presente trabalho, mas os referenciamos para aqueles que possam se interessar no aprofundamento da questão.

Embora não coloquemos em destaque neste texto, pode-se perceber na documentaçáo que em boa parte das reunióes da congregaçáo existem preocupaçóes com as condiçôes materiais da escola, com os professores se dispondo até ao dispêndio pessoal para aquisição de certos bens ou para a melhoria de algumas condiçóes essenciais para o ensino. Também estão presentes cuidados com as condiçôes higiênicas, com os compêndios escolares, com a organização didáticopedagógica, com a montagem de uma biblioteca para a escola, etc. Além disso, percebe-se a preocupação com as relaçóes com o poder local e estadual, inclusive com a forma de governo do país, que será alterada de monarquia para república em meio aos trabalhos escolares.

O encerramento das atividades dar-se-á em 1905, por motivos alheios à própria escola. Será decisão unilateral do governo mineiro que, premido pelos problemas 
econômicos, e preocupado em promover uma mudança significativa no sistema estadual voltado para a instruçáo popular, promove essa e outras alteraçóes no setor educacional. No entanto, nas atas da congregaçáo encontraremos em 12 de outubro de 1891, sinais do garroteamento que já se vinha fazendo sobre as escolas normais do estado, atingindo particularmente a de Montes Claros:

O Sr. Director diz que reunia a presente congregação para tomar conhecimento de um officio do snr. Dr. Secretario do Interior no qual recomenda que a congregação resolva sobre si, acceitando a disposição da nova lei de instrucção publica, continua a funccionar, mantendo a Escola. Pede a palavra o snr. Professor Luis Gregorio e diz que, comquanto a reducção dos ordenados seja tal que torna-se quase impossível a presente manutenção do professorado, é de parecer que se deva acceitar a disposiçáo da lei no 318 porquanto o grande sacrifício desta colectividade terá esta compensação: náo deixar morrer, não privar a cidade e a Zona do Norte do Estado deste [único] progresso que lhe foi concedido, a Escola Normal e mais, que sendo, como são na sua maioria pobres os alumnos que freqüentam a Escola, pensava que se devia abrir máo acceitar-se o [?] de um dispositivo daquella lei que manda cobrar taxa de matricula para ser a sua somma repartida entre os professores. (MINAS GERAIS, 1887-1903, grifo nosso).

\section{A questão regulatória: organização das normas, do espaço e da vida escolar}

O livro de atas sobre o qual nos debruçamos tem seu registro de abertura datado de 24 de outubro de 1887, sendo a primeira ata registrada em 3 de dezembro desse mesmo ano. Com relação ao item em pauta, em diversos momentos entram em discussão aspectos de regulação da vida escolar, mas a aprovação do projeto do regulamento da escola aparecerá apenas em 21 de maio de 1891, quando anota-se que a comissão encarregada de preparar o regimento interno da Escola Normal apresenta a proposta, que não está incluída no livro de atas e a qual não tivemos acesso. Provavelmente o regulamento foi perdido ou ainda náo identificado em algum arquivo. Propostas de mudanças são apresentadas e aprovadas pelos professores, sendo o conjunto; chamado de regulamento da escola, aprovado em seguida, nesse mesmo dia. 
Em diversos momentos nas atas, no entanto, podemos perceber particularidades desse regulamento, como na reuniáo de 15 de novembro de 1888, quando, após discussão sobre problemas disciplinares, se estabelece

[...] que nos intervallos das aulas haja absoluta incommunicabilidade entre os alumnos e as alumnas, devendo estas entrar para o saláo da aula pratica do sexo feminino, no fim de cada aula, e só dali sair para outra aula ou para suas casas, e os alumnos, durante os mesmos intervallos, ficarão na aula pratica do sexo masculino, ou na varanda do mesmo lado. (MINAS GERAIS, 1887-1903).

Já na ata da congregação, do dia 13 de fevereiro de 1894, encontramos um outro elemento contido no regulamento que precisava de definição e que seria debatido na reuniáo dos professores:

O Sr. director finalmente declarou que uma das disposiçóes do Regulamento em vigor ainda não se tinha comprida; essa disposição era a que se referia ao vestuário distinctivo dos alumnos-mestres; e que portanto convidava ao professor Serafim Teixeira para se encarregar para apresentar a forma que melhor the parecer esse vestuário. (MINAS GERAIS, 1887-1903).

Com relação a esse detalhe das vestimentas dos alunos da escola (alumnos-mestres), cabe notar que, no dia 16 de março de 1895, foi feita uma representação dos alunos, pedindo "[...] alteração aliás mudança da fazenda até então adoptada. O professor Camillo Prates propoz que se autorizasse ao Director a fazer alteração que entendesse, depois de ouvidos os reclamantes, continuando por em quanto o uniforme adoptado, proposta que foi aprovada" (MINAS GERAIS, 1887-1903).

Por essa inserção, notamos que, apesar do controle exercido pelo diretor e pelo corpo docente sobre a vida escolar, havia algum espaço de negociaçâo, envolvendo demandas oriundas dos alunos. Em outros momentos aparecem novas reivindicaçóes sobre outras temáticas, como sobre o direito dos alunos de prestar exames, presente na ata do dia 19 de maio de 1898 e atendida pelos professores, mas que foge à temática do presente estudo. Assim, poderíamos caracterizar essas relaçóes, seguindo o sentido dado por Michel de Certeau (1998, p. 45), como politização das práticas cotidianas: 
[...] a cultura articula conflitos e volta e meia legitima, desloca ou controla a razáo do mais forte. Ela se desenvolve no elemento de tensóes, e muitas vezes de violências, a quem fornece equilíbrios simbólicos, contratos de compatibilidade e compromissos mais ou menos temporários.

No dia 17 de novembro de 1894, a questão do regulamento voltará à cena, com a apresentação de nova proposta regulatória para a Escola Normal de Montes Claros. Conforme consta no livro:

O professor Luiz Gregorio pedindo e obtendo a palavra depois de ter feito algumas consideraçôes como relator, apresentou o projecto de regimento interno que deve ser aprovado para esta Escola e leu o parecer da mesma commissão [nomeada na reuniáo da congregação, de 13 de fevereiro de 1894], pedindo que fosse logo posto em discussão o aludido regimento. $\mathrm{O}$ professor Justino Guimarães pedindo e obtendo a palavra fez diversas consideraçóes no sentido de [provar] que estando em gozo de férias, náo havia necessidade de ser aprovado com açodamento o regimento por quanto era uma lei que devia ser discutida com toda calma porque n'ella se estabeleceria differentes obrigaçóes a diversos empregados e que por isso propunha que fosse designado o dia 15 de fevereiro para se discutir e aprovar o aludido regimento interno; sendo aceita esta proposta foi designado o dia 15 de fevereiro para aquelle fim. (MINAS GERAIS, 18871903, grifo nosso).

Houve atraso no encaminhamento dos debates, mas na reunião de 16 de março de 1895 foi discutido, emendado e aprovado o dito regimento interno, embora o texto final não tenha sido registrado na ata. Nomeia-se a comissão de redação final, cujos resultados foram aprovados na reunião da congregação de 21 de março de 1895. Novamente, não foi possível ter acesso ao texto do regimento.

Além dessas preocupações com a regulamentação do cotidiano, encontramos outras manifestaçóes voltadas para as condiçóes materiais da escola. Em alguns casos específicos, os próprios professores dispunham-se ao sacrifício de seus bolsos para garantir as condiçóes de funcionamento da instituição, como podemos perceber na ata do dia 27 de dezembro de 1889, quando o professor Camillo Prates pede a palavra e diz que era imprescindível a aquisição de 
[...] um relógio para a escola, pois de modo [diverso], não se podia bem regular os trabalhos d'ella e por isso propunha que os professores se quotizassem para aquelle fim, declarando mais que subscrevia com dez mil reis e pedio que seus collegas se manifestassem. (MINAS GERAIS, 1887-1903).

Sobre esse detalhe do controle do tempo, o olhar do diretor volta-se ainda para o trabalho dos docentes e controle sobre o tempo e a qualidade das atividades que desenvolviam na escola, desnudando outros elementos do dia a dia escolar, muitas vezes dissimulados por conta de atitudes corporativas. $\mathrm{Na}$ ata do dia 2 de outubro de 1895 encontramos um registro que nos auxilia a compreender um pouco mais o cotidiano laboral no interior da escola e os mecanismos de controle estabelecidos:

Depois do que, o mesmo Sr. Director fez ver á congregação que, apezar de ser isso disposição da lei que nos rege, fazia-se mister, para maior regularidade dos trabalhos da Escola, que todos os professores chegassem pontualmente, á hora designada no horário, ficando, de vez, abolido o inveterado costume de assignarem o ponto até um quarto de hora depois; em o que foi unanimemente aprovado pela congregação. Ficou ainda resolvido pela congregação, depois de consulta do director, que o professor, que, dizendo dar duas ou mais aulas no dia, deixar de dar qualquer dellas, sem justo motivo, perderá o ordenado do dia, digo, os vencimentos do dia. (MINAS GERAIS, 1887-1903).

O irônico nessa situação é que a averiguação dos atrasos provavelmente fora feita por meio do relógio proposto para aquisição em 1889, com recursos dos docentes, que acabaria por ser utilizado contra eles, para o efetivo acompanhamento dos horários de entrada e saída das aulas e de outras atividades.

\section{A indisciplina se faz presente}

Em vários momentos encontramos registros voltados para os atos de indisciplina dos alunos, que sofrem diversas punições por essas manifestações. A fuga das normas não é homogênea, nem contínua, apresentando-se sob as mais diferentes formas. Também variam os agentes envolvidos, combinando atritos entre alunos do sexo masculino, entre alunos do sexo masculino e feminino, 
entre alunos e professores, entre alunos e funcionários e mesmo manifestaçóes que atingem a autoridade do diretor. Em seguida, apresentaremos algumas dessas ocorrências, bem como as providências tomadas pela congregação e as devidas penas aplicadas. O primeiro caso identificado é noticiado na ata do dia 15 de novembro de 1888:

Em seguida, o mesmo Sr. Director communicou que, havendo recebido, no dia 13 do corrente, uma queixa do porteiro da Escola, contra o alumno mestre Elydio Duque Rodrigues, que o desrespeitára e quisera mesmo aggredil-o, em conseqüência de uma admoestação que lhe fizera por uma falta commetida, - no dia seguinte se dirigiu á Escola e censurou o procedimento do referido alumno, reprehendendo-o em particular, por ser este um dos castigos estabelecidos pelo regimento. No officio dirigido pelo Sr. porteiro ao Sr. Doutor Director, denunciou aquelle também que muitos alumnos-mestres iam armados á Escola, e faziam uso dessas armas dentro do estabelecimento. Em vista do que, e por informaçóes particulares dadas a alguns srs. professores, as quaes confirmam o facto denunciado, a congregação resolveu acabar com semelhante abuso, de perigosas conseqüências e de grande inconveniente para a boa disciplina da Escola. Para esse fim, resolveu que será expulso da Escola qualquer alumno que fôr ás aulas armado, ou que, por qualquer forma, usar de arma dentro do estabelecimento, ficando a respectiva inspecção a cargo dos professores e dos demais empregados da Escola. A congregação deliberou mais que, quando um alumno commeta falta táo grave que deve ser de prompto retirado da aula, e o seja pelo respectivo professor, este communicará o ocorrido ao director da Escola, o qual immediatamente convocará a congregação para deliberar a respeito. O alumno, com quem se tiver dado o occorrido, será chamado perante a congregação, e se não quiser comparecer, ou si, comparecendo, não der satisfação de sua falta que seja acceita pelo professor, será considerado incorrigível, e como tál expulso da escola. (MINAS GERAIS, 1887-1903).

Por essa passagem, se tomarmos esse exemplo como passível de ser estendido a outras localidades, percebemos que as relaçóes no interior das escolas secundárias mineiras no final do século XIX não seriam muito seguras, dado o reconhecimento do uso generalizado de armas por parte dos alunos de Montes Claros. Apesar de 
não ser registrado qualquer incidente específico com relação ao uso dessas armas, o perigo era iminente e as providências resolvidas na reuniáo da congregação demonstram a percepção da dimensão do problema. De qualquer forma, fica explícita a disseminação do porte e uso de armas no convívio social, uma atitude comum em cidades interioranas do Norte de Minas Gerais à época e, inclusive, no país, como pode também ser observado em disposiçóes regulamentares de outros colégios de Minas Gerais em períodos semelhantes, como as que se encontram nos regimentos do Colégio Marista Diocesano, de Uberaba e das Escolas Dom Bosco, de Cachoeira do Campo, que proibiam levar para o interior dos internatos "[...] canivetes, facas, navalhas ou armas de fogo de qualquer espécie" (GONÇALVES NETO, 2014, p. 114). Um segundo registro de indisciplina iremos encontrar na ata do dia 25 de junho de 1891 :

Dada a palavra pelo Director ao professor Joáo Antonio Gonçalves Chaves, este, depois de ter explicado o procedimento incorrecto e irregular do alumno-mestre Joáo de Deus Oliveira, tanto dentro como fora da Escola, implantando assim a indisciplina na aula, pediu que fosse o mesmo alumno-mestre João de Deus expulso temporariamente a contar do dia 20 de junho a 20 de julho. Posto a discussão não houve quem tomasse a palavra; e em seguida foi posta em votação, sendo unanimemente approvada a expulsão temporaria do referido alumnomestre. (MINAS GERAIS, 1887-1903).

Nesse caso, devemos observar que não se apresenta o procedimento específico do aluno que justificou a intervenção da congregação, havendo apenas a comunicação do fato por parte do professor e a pronta aplicação da pena. Apesar da rapidez da congregação, enquadrando o aluno com a chamada expulsão temporária, outro incidente será anotado nas atas desse mesmo ano. $\mathrm{Na}$ reunião de 20 de agosto, o professor Antonio Chaves de Queiroga diz que foi desautorizado por um aluno durante uma aula prática, solicitando aos professores que deliberassem sobre tão grave e lamentável incidente, e que pedia que se nomeasse uma commissão que sindicasse o facto ocorrido. A comissão é nomeada e, no dia 22 de agosto de 1891, apresenta seu parecer:

Os abaixo assignados, membros da commissão que, na congregaçáo do dia 18 do corrente, foi pelo snr. Director da Escola Normal desta Cidade nomeada para syndicar do procedimento que teve o alumno mestre José Bento 
Rodrigues Valle por occasião de assistir a aula pratica de exercícios práticos, regida pelo Professor Antonio Teixeira Chaves de Queiroga, [e] no caso de ter sido o procedimento d'aquelle alumno incorreto, dar sua opiniáo sobre a pena que deve lhe ser imposta, bem desempenhou-se desta missáo. A commissão depois de ter ouvido a diversos alumnos da Escolla, que presenciarão o facto, ficou convencida de que o alumno mestre José Bento Rodrigues Valle desautorizou ao professor Antonio Queiroga não obedecendo a sua chamada quando se retirou bruscamente da [pedra] onde fazia exercícios práticos de ortographia. A commissão vê neste procedimento do alumno uma desobediência formal ao professor e por isso entende que náo pode elle continuar a freqüentar as aulas sem que seja punido; e como é certo que a expulsão ultima pena que a um alumno pode ser imposta, trar-lhe-há uma mancha [?], e mais, suppondo a commissão que compenetrando o alumno de seu máo procedimento, pode corrigir-se d'elle, entende que, ficando reservada aquella para reincidência, caso haja, seja o alumno punido com uma reprehensão publica feita pelo snr. Director na presença da Congregação, aliás do corpo docente da Escola e alumnos. (MINAS GERAIS, 1887-1903).

O parecer foi aprovado por unanimidade, devendo notar-se, no entanto, a variação na pena infligida, sendo dessa vez apenas uma repreensão pública. Adicionalmente, no correr $\mathrm{da}$ ata, fica também determinado que se "[...] communicasse todo o occorrido ao Pai do referido alumno-mestre" (MINAS GERAIS, 1887-1903).

Nova manifestação digna de registro no livro de atas foi assinalada no dia 18 de maio de 1897. Apesar de longa, é importante manter a citação na íntegra, para que o leitor possa acompanhar o relato, agora envolvendo uma personagem que ainda não se fizera presente, uma representante do sexo feminino:

Em seguida o Sr. director leu á congregação a seguinte representação: 'Srs. membros da congregação. Pela primeira vez tenho o desprazer de convocar extraordinariamente o corpo docente da escola para uma congregaçáo que deve resolver sobre uma facto grave de indisciplina e insubordinaçáo por parte de alumnos e que exige a apllicaçáo de uma das penas do nosso Regimento. O facto deu-se da maneira seguinte: Avisado pela professora inspectora de que a alumna D. Joana Petronilha dos Santos havia faltado á 
aula de dezenho do primeiro anno sem motivo justificado e achando-se a mesma alumna dentro do estabelecimento da escola, fiz ver a esta alumna que suas faltas repetidas tiravamlhe o direito a qualquer reclamação no fim do anno lectivo. Retirando-me em seguida para a secretaria, fui chamado pouco depois pela inspectora que, julgando-se offendida e injuriada por palavras pouco cortezes com que fora tratada pela referida alumna, que attribuia-lhe a denuncia da falta commettida, reclamava punição severa e immediata para um tal acto de indisciplina. Estranhando semelhante procedimento por parte de uma moça e julgando ser indispensável para a boa marcha dos trabalhos escolares não quebrar em um só ponto a força moral de que deva achar-se revestido o pessoal docente da escola e particularmente a inspectora, a quem incumbe zelar pela boa ordem e respeito que deve observar-se no saláo de estudo, mandei chamar à secretaria a referida alumna d. Joannna Petronilha dos Santos, observando-lhe que, pela reincidência e gravidade de suas faltas, resolvi applicar-lhe a pena constante da lettra $-\mathrm{C}-$ do art. $8^{\circ}$ do Regimento interno. Tanto bastou para que a referida alumna prorrompesse em uma serie de palavras injuriosas contra o director e contra todo o pessoal da escola, palavras que deixo de reproduzir aqui pelo respeito que devo à congregação, e que foram ouvidas por mim, pelo secretario e pelos empregados da escola. Exposto o facto deste modo e julgando que semelhante acto de indisciplina deva ser punido com a pena de que trata o art. 157 do Regulamento e $8^{\circ}$ do regimento, peço aos collegas que se manifestem, a respeito, afim de não demorar a resoluçáo de uma medida que venha desaffrontar a injuria atirada á escola'. Posta em discussão a materia desta representação, o sr. professor João Chaves foi de parecer que se addiasse a resolução da mesma para outra congregação em que se achassem presentes todos os membros do corpo docente, attenta a importância do assumpto. Indicou o mesmo Sr. professor que fossem de novo convocados a comparecer os professores faltosos; mas esta sua indicação foi rejeitada, visto como em officio declaram aquelles professores deixarem de comparecer por incommodo de saúde. Em discussão a proposta do Sr. professor Joáo Chaves, contra ella se manifestaram os srs. professores Antonio dos Anjos, Luiz Gregorio, Pedro Guimarães. Posta a votos, foi a mencionada proposta rejeitada por unanimidade 
de votos. Continuando a discussão sobre a matéria da representaçáo, depois de haver se manifestado a respeito a maioria da congregação, foi a mesma approvada, resolvendo a congregação por unanimidade de votos applicar á alumna d. Joanna Petronilha dos Santos a pena da lettra C do art. $8^{\circ}$ do Regimento; e deste acto fez-se immediatamente sciente por officio o pai da referida alumna.

Pelo exposto, observa-se que os atos de indisciplina náo eram exclusividade dos alunos do sexo masculino, devendo-se anotar, inclusive, o espanto do diretor com relação ao procedimento por parte de uma moça e ao linguajar por ela utilizado, o que expóe uma atitude masculina ainda muito voltada para os cuidados para com o sexo feminino. Não se pode deixar também de observar a atitude belicosa da aluna ao tirar satisfaçóes com a inspetora, por conta do repasse dos fatos feito por ela ao diretor, bem como sua atitude provocativa diante do mesmo diretor, muito distante do que se poderia esperar dos padróes de comportamento do sexo frágil ao final dos oitocentos. Todos esses elementos nos permitem identificar uma atmosfera de enfrentamento ou de resistência dos alunos para com os docentes, uma recusa à sujeição às normas estabelecidas, bem como a postura decidida dos professores no sentido de restaurar sua autoridade e não permitir o afrontamento.

No ano seguinte, em 4 de março de 1898, as atas voltam a registrar novo incidente, agora de maior significância, pois envolveu o depoimento de diversos alunos que entraram no processo como testemunhas:

O Sr. Director communica que a congregação se reunio para deliberar sobre a pena que devia ser applicada aos alumnos Francisco de Alencar Durães e Armenio Rodrigues Sarmento que naquele dia haviam quebrado a disciplina da Escola, tendo entre elles havido pequeno conflito na porta do edifício. Informou o Sr. Director que na escola se achavam os alludidos alumnos bem como quatro collegas daqueles que haviam assistido o facto. A congregação ouviu então singularmente os alumnos e assim aos srs. Osorio Chaves, Philomem Ribeiro, Cicero de Sousa e também o porteiro e pelas informaçóes destes com daqueles ficou verificado que o alumno Francisco de Alencar Durães esbofeteou ao seu collega Armênio Sarmento, tendo havido entre elles trocas de palavras injuriosas. Pedindo então a palavra o snr. Camillo Prates, propoz que fosse aplicado ao alumno F. de Alencar Durães a pena de vinte dias de suspensão dos 
direitos de freqüência e a metade daquella pena ao alumno Armenio Sarmento. O snr. Professor Spyer pensa que, devido a differença de grau de culpabilidade entre eles, visto como ficou também provado que o primeiro delles havia ameaçado também ao porteiro da Escola, convidando-o para a lucta, devia ser imposta ao ultimo pena mais branda e propóe que seja esta a de reprehensão em particular. Declaram-se suspeitos para votar os snrs. Antonio dos Anjos e João Froes que são parentes do alumno Armenio Sarmento. A congregação depois de pequena discussão não julga os suspeitos e o snr. Director convida aos collegas professores para se manifestarem. O snr. Antonio dos Anjos vota pelas penas propostas pelo snr. Camillo Prates com a modificação indicada pelo Director e assim se manifesta a congregaçáo, excepção do professor João Froes que não julga o alumno Armenio Sarmento passivel de pena pelo facto relatado. O Sr. Director declara que vai communicar aos alumnos esse resultado mandando que se lance na matricula a nota respectiva.

Nesse extrato percebemos um outro aspecto do cotidiano escolar ${ }^{4}$, para além dos conflitos que se sucediam entre os alunos e entre eles e os professores. Vemos aqui, como seria de se esperar em uma comunidade náo muito extensa e onde o acesso à educação de nível secundário não era generalizado, o conflito de interesses que se estabelece com a presença de relaçóes de parentesco entre alunos e professores. E vemos como as questóes de sangue se sobrepóem aos interesses disciplinares da escola, com o professor parente fazendo a defesa do aluno transgressor. Apesar da punição ser aplicada, o seu alcance ficou bem reduzido.

No dia 8 de março de 1898 é convocada uma reunião extraordinária da congregaçáo para tratar de um problema disciplinar melindroso, pois envolvia um entrevero entre uma aluna e um aluno:

Communicou o snr. Director que convocara a presente reunião para tratar de um facto que a seu modo de ver não devia subir a tela de discussáo em congregaçáo, porquanto

4 Para Michel de Certeau (2003, p. 31), “[...] o cotidiano é aquilo que nos é dado cada dia (ou que nos cabe em partilha), nos pressiona dia após dia, nos oprime, pois existe uma opressão no presente. [...] o cotidiano é aquilo que nos prende intimamente, a partir do interior." Ademais, a cultura envolve todo o cotidiano dos indivíduos, perpassa a atividade humana, mas só se efetua quando as práticas sociais conferem significado para os indivíduos que as realizam, ou seja, a cultura como prática que produz significado. 
era de caracter melindroso e sobre o qual devia-se guardar toda reserva possível. Trata-se, continuou elle, de impor-se pena a um alumno - o snr. Ezequias Alves Sarmento que ao retirar-se de um dos salóes onde funciona a aula do primeiro anno havia, conforme queixa de uma alumna, desacatado-a, puchando-lhe a trança. Que no mesmo dia consultando três colegas seus que se achavam na secretaria - os snrs. Camillo Prates, João Chaves e Luis Gregorio, estes pensaram e aconselharam que seria melhor e mais conveniente que elle, director, impusesse a pena sem divulgar-se o facto, mas que finalmente attendendo a reclamação de alguns collegas que na cidade souberam do facto e vieram sobre ele pedir providencias, havia convocado a presente congregação e a ela submetter a questão. Pede a palavra o professor João Chaves e declara ser sua opiniáo que a questáo não deve ser discutida. O professor Camillo Prates julga que os collegas que pediram providencias devem propor as medidas que julgarem convenientes para a punição do alumno. Pede a palavra o professor Antonio dos Anjos que diz ter sabido por particulares do facto e que pensa dever elle ser discutido em congregação; que indagando do snr. Director, na directoria da Escola, este informou-lhe de que as providencias seriam tomadas e que o alumno náo voltaria a escola. Pensa, porem, o professor que náo pode o Director por si punir o alumno e que somente a congregação poderá fazel-o. Pede a palavra o professor J. Prates e propõe que a congregação não discuta o facto e delegue ao snr. Director os poderes necessários para agir na questão. Em discussão a proposta, manifestase por ella o snr. Camilo Prates e Antonio Queiroga, requerendo o ultimo que da acta constasse o seu voto. Em votaçáo a proposta foi unanimemente aprovada. Declara o snr. Director que vai punir ao alumno, conforme julgar necessário e que na matricula mandará lançar a competente nota. (MINAS GERAIS, 1887-1903).

Encontramos nessa passagem alguns dados interessantes. Primeiro que, apesar dos cuidados disciplinares na separação dos sexos, em alguns momentos, os encontros entre eles ocorriam e podiam enveredar para o conflito. Segundo, o vazamento das informaçóes sobre o que ocorria na escola, demonstrando que a comunidade local acompanhava o que acontecia no seu interior, exercendo uma espécie de pressão social sobre o andamento 
das atividades. Terceiro, que o diretor em muitos casos devia aplicar punições ditas menores aos alunos, sem passar o caso pela congregação, o que denota que as ocorrências disciplinares deveriam ser muito maiores do que estáo expostas nas atas. E por último o caráter melindroso do registro, por envolver entrevero entre aluno e aluna, o que colocava em risco o bom nome da escola, ao permitir que um aluno ofendesse a um representante do sexo feminino. Delega-se, inclusive, ao diretor liberdade para aplicar, com a devida discrição, a punição conforme julgue conveniente.

Os atos de insubordinação continuam sendo relatados nas atas. No dia 9 de janeiro de 1899, o diretor comunica indisciplina praticada na aula prática do sexo masculino pelos alunos Antonio Rodrigues Froes Neto e João Chaves Junior:

O professor Camilo Prates, depois de ouvir a exposição dos factos feita pelo professor Altino Teixeira A. Carvalho, propoz que a congregaçáo delegasse poderes ao seu presidente para officiar aos Paes dos alumnos relatando o facto. Esta proposta foi approvada e levantou-se a sessão. (MINAS GERAIS, 1887-1903).

No dia 9 de abril de 1901, novo caso é apresentado, nomeando-se comissão para a sindicância, com o seguinte encaminhamento:

Ouvidos demais alumnos que assistiram os factos, a comissáo lavra por escripto o seu parecer opinando que devem ser suspensos por três dias os alumnos João Chaves Junior, Sebastião Tupinambá, Antonio Rodrigues Froes Netto e José Eustachio. Este parecer em discussão foi unanimemente aprovado. (MINAS GERAIS, 1887-1903).

Um último registro foi encontrado na ata de 6 de maio de 1903, e é importante por conter a punição mais forte aos alunos que foram a julgamento, a expulsão definitiva:

Em seguida o Sr. Director declarou a congregaçáo, que havia convocado a presente sessão, como [dever para fazer constar] aos snrs. Professores nos termos do artigo 178 do Regulamento em vigor, para submetter a discussão da collectividade um facto grave occorrido nesta escola no dia dois do corrente mez, facto pelo qual era responsável, como auctor, o alumno mestre Virgilio Guedes Chaves. Depois de haver exposto a Congregação em que consistia 
o dito facto com todas as circunstancias que o revestiram, informou o mesmo Sr. Director a mesma congregaçáo que o referido alumno já tinha sido punido por faltas que cometteu anteriormente com as penas dos numeros 1 e 2 do artigo 171 do Regulamento citado. Em seguida fez se ouvir o professor Prates, que informou o que sabia de vista a cerca do facto. Depois d'elle foram chamados e ouvidos o continuo Joấo Augusto [Milica] e o alumno mestre Sebastião T. de Carvalho, que depuserão o que a respeito sabião. Depois de procedidas essas minuciosas averiguaçóes, foi accorde a congregação em reconhecer que se tratava de um facto de summa gravidade, attentatorio da moralidade da Escola, por quanto o alumno mestre accusado, depois de injuriar e esbofetear um seu condiscipulo, entrou em pugilato com outros condiscipulos seus, que accudirão em socorro a este; e quando o mencionado alumno, ao retirar-se ouvia dizer do Director da Escola que ia convocar uma Congregaçáo para sindicar do facto, respondeu-lhe insolentemente e em termos obscenos que riscasse seu nome da matricula, pois não voltaria mais a Escola. Em seguida, o professor Spyer propoz que se infligisse ao alumno a pena de privação de freqüência e exames durante um anno, apesar de reconhecer insuficiente essa pena a vista da gravidade do delicto. Esta proposta náo foi acceita pela Congregação a qual por indicação dos srs. professores José Rodrigues Prates e João Chaves, resolveu por cinco votos auctorizar o Sr. Director applicar, como de facto applicou ao dito alumno Virgilio Guedes Chaves a pena de expulsão definitiva da Escola, devendo-se dar baixa no livro de matricula com a devida nota nos termos do art. 199 do Regulamento. (MINAS GERAIS, 1887-1903).

Esse último caso é exemplar para demonstrar como se prezava a manutenção da disciplina no interior da escola, com a pena chegando à decisão radical da exclusão do aluno. Por outro lado, esse e os outros exemplos apontados expóem claramente a natureza conflituosa das relaçóes escolares, tanto pela chegada às vias de fato entre os alunos ou até ao convite de aluno para semelhante atitude para com funcionários da escola, como pelos constantes entreveros acontecidos entre alunos e professores. 


\section{Considerações finais}

Pretendíamos com este trabalho expor um pouco do cotidiano da Escola Normal de Montes Claros, como representativo do cotidiano das escolas de formação de professores do estado de Minas Gerais nos derradeiros anos do Império e no início da República. Não no sentido de uma generalização, mas permitindo compreender, ainda que de forma parcial, que as relaçóes escolares poderiam acontecer de forma semelhante em outras instituiçóes. $\mathrm{Ou}$, pelo menos, convidar o leitor para estudos comparativos de outras unidades, para que seja possível estabelecer pontos de aproximação e de distanciamento, permitindo compreender de forma mais ampla que os processos de transmissão/ reprodução cultural são "[...] resultado de muito trabalho duro realizado pelos pais, professores, clérigos, empregados e outros agentes envolvidos no processo de socializaçáo" (BURKE, 2002, p. 175). Portanto, a permanência e disseminação de uma dada cultura não é algo espontâneo, inocente, mas fruto de trabalho articulado e interessado de atores diversos que agem inculcando os valores que consideram válidos.

Da mesma forma, procurou-se delimitar parcialmente a cultura escolar que se desenvolvia no interior da instituição, destacando-se particularmente os aspectos disciplinares, sua presença evidente, as práticas de resistência, a ação controladora da escola, as puniçôes, etc. Também se buscou oferecer ao leitor a oportunidade de refletir sobre as relaçóes entre o passado e o presente no campo da educação, tomando-se as mudanças e permanências que se manifestam no interior da escola relacionadas às questóes disciplinares, à violência, aos poderes constituídos, pois o uso dessas fontes e das categorias aqui elencadas; pode ampliar as possibilidades de estudos no campo da história da educação, ao permitir a compreensão de suas manifestações, do funcionamento da maquinaria escolar, bem como das práticas daí decorrentes, isso é, as abordagens históricoeducacionais que se apoiam na história cultural, se debruçam sobre as "[...] estratégias simbólicas que determinam posiçóes e relaçóes e que constroem, para cada classe, grupo ou meio, um 'ser-percebido' constitutivo de sua identidade" (CHARTIER, 2002, p. 73, grifo do autor).

Espera-se, na continuidade dos estudos, aprofundar os elementos aqui levantados e buscar documentação complementar que permita avançar sobre os resultados alcançados, propondo novas perspectivas para se refletir sobre o processo de formação de professores para a instrução popular nos anos finais do Império e na Primeira República no Brasil. 


\section{Referências}

ARAUJO, J. C. S.; FREITAS, A. G. B.; LOPES, A. P. C. (Org.). As Escolas normais no Brasil: do Império à República. Campinas: Alínea, 2008.

BRASIL, H. O. História e desenvolvimento de Montes Claros. Belo Horizonte: Lemi, 1983.

BURKE, P. História e teoria social. São Paulo: Editora UNESP, 2002.

CERTEAU, M. A invençáo do cotidiano: artes de fazer. Petrópolis: Vozes, 1998.

CERTEAU, M. A invençáo do cotidiano: morar, cozinhar. Petrópolis: Vozes, 2003.

CHARTIER, R. À beira da falésia: a história entre certezas e inquietude. Porto Alegre: Editora da UFRGS, 2002.

DURÃES, S. J. A. "Escola primária e formação docente: ensinando a ser professor (a) na Escola Normal de Montes Claros (1889-1906). In: GONÇALVES NETO, W.; CARVALHO, C. H. (Org.). O município e a educaçáo no Brasil: Minas Gerais na Primeira República. Campinas: Alínea, 2012. p. 89-112.

FONSECA, T. N. L. História da Educação e História Cultural. In: VEIGA, C. G.; FONSECA, T. N. L. (Org.) História e Historiografia da Educaçáa no Brasil. Belo Horizonte: Autêntica, 2003. p. 49-75.

GONÇALVES NETO, W. "Educação christã da mocidade": regulamentação da vida escolar em colégios católicos de Minas Gerais (1863-1911). Cadernos de História da Educaçáo, Uberlândia, v. 13, n. 1, p. 99-117, jan./jun. 2014.

JULIA, Dominique. Traduçáo de Gizele de Souza. A cultura escolar como objeto histórico. Revista Brasileira de História da Educação, Campinas, n. 1, p. 9-43, jan./jun. 2001.

MATTOS, C. L. G.; COELHO, M. I. M. Violência na escola: reconstruindo e revisitando trajetórias e imagens de pesquisas produzidas por no Núcleo de Etnografia em Educação entre 1992 e 2007. In: MATTOS, C. L. G.; CASTRO, P. A. (Org.). Etnografia e educaçáo: conceitos e usos. Campina Grande: EDUEPB, 2011. p. 195-219.

MINAS GERAIS. Arquivo Público Mineiro. Atas da Congregaçáa dos professores da Escola Normal de Montes Claros. Seção Provincial, Fundo Instrução Pública, IP 118, 1887-1903. 
OLIVEIRA, A. C.; ALVES FILHO, E. "Montes Claros no contexto educacional mineiro: (im)postura municipal e organização escolar no limiar da República. In: GONÇALVES NETO, W.; CARVALHO, C. H. (Org.). O município e a educaçáo no Brasil: Minas Gerais na Primeira República. Campinas: Alínea, 2012. p. 201-232.

PINHO, A.; MARIAN, D. SP tem quase 2 professores agredidos ao dia; ataque vai de soco a cadeirada. Disponível em: <http://www1.folha.uol.com. br/educacao/2017/09/1919146-sp-tem-quase-2-professores-agredidos-ao-diaataque-vai-de-soco-a-cadeirada.shtml>. Acesso em: 24 set. 2017.

VIANNA, N. Efemérides montesclarenses - 1707-1962. Rio de Janeiro: Irmãos Pongetti Editores, 1964.

VIANNA, U. S. Monographia do Municipio de Montes Claros: breves apontamentos historicos, geographicos e descriptivos. Bello Horizonte: Imprensa Official do Estado de Minas Geraes, 1916, p. 100.

VIDAL, D. G.; SCHWARTZ, C. M. (Org.). História das culturas escolares no Brasil. Vitória: EdUFES, 2011. 